\title{
História das \\ teorias da \\ comunicação
}

Nos últimos ANOS, Armand Mattelart vem realizando um audacioso projeto: escrever a história das mídias, das teorias que as envolvem e dos processos de comunicação sob os mais diferentes aspectos. Do ponto de vista do leitor brasileiro, primeiro foi a vez de Comunicação-Mundo (Petrópolis, Vozes. 1994). Agora, a Loyola lança este História das teorias da comunicação. Está ainda faltando La mondialization de la communication, de 1996, que já recebeu tradução espanhola mas encontra-se inédito entre nós.

Se Comunicação-Mundo organizava-se em três grandes blocos, a guerra, o progresso tecnológico e a cultura, este novo trabalho é mais fragmentário mas, ao mesmo tempo, mais definido. Ele se desdobra em sete grandes capítulos que vai abrangendo as diferentes fontes teóricas, espalhadas pelas diferentes disciplinas que, ao longo dos dois últimos séculos, e às vezes até bem antes, terminaram por influenciar a maneira de conceber, discutir e pensar os processos de informação (consequentemente, de comunicação) existentes hoje em dia no mundo. Por isso mesmo, a mesma característica do livro anterior, ainda que em percentuais menores, a reiteração de alguns enfoques, ainda que sob novas perspectivas, ocorre também neste trabalho.

Partindo do reconhecimento de que "a noção de comunicação recobre uma multiplicidade de sentidos" (p. 9), Mattelart evidencia que a ciência da informação, por ser disciplina nova, dependeu de outras muitas disciplinas para formar seu corpus conceitual. Assim, a partir das sociologia, da antropologia e dessas áreas afins, Mattelart recupera, dentre outros, o contemporâneo conceito de rede de comunicação (p. 15 e ss.), que reencontrará no último capítulo (p. 157 e ss.), quando sintetiza: "a sociedade é definida em termos de comunicação, que é definida em termos de redes". Assim, retoma a perspectiva da cibernética, sublinhando que a mesma " substitui 
a teoria matemática da informação" na contemporaneidade.

Reunindo os princípios da Escola de Chicago, e depois destacando a importância da Escola de Palo Alto, recuperando a contribuição vanguardista de Harold Lasswell e os princípios da mass communication research (p. 36 e ss.), Mattelart chega ao modelo matemático de Shannon, que cruza com o conceito cibernético de Wiener, para depois enveredar pela indústria cultural e as perspectivas desdobradas, a partir das matrizes marxistas, pela Escola de Frankfurt e, complementarmente, pelo estruturalismo francês e norteamericano, bem como pelos cultural studies de Birmingham, até o conceito de sociedade global que, afirma ele, tem sua origem no conhecido mas nem sempre justamente valorizado ensaio de Marshall McLuhan War and peace in the global village de 1969.

O volume incursiona ainda pela valorização das práticas cotidianas, revalorizando a contribuição da etnometodologia, do agir comunicativo de Jürgen Habermas - que dava um passo além da teoria crítica frankfurtiana para chegar aos estudos dos usos e gratificações dos funcionalistas norte-americanos, concluindo pela potencialidade híbrida dos processos de comunicação como parte de sua natureza.

A lição mais genérica e universalizadora que se pode tirar desta nova obra de Mattelart é que, na verdade, tanto uma história dos meios de comunicação quanto dos processos, suas tecnologias ou teorias a respeito da comunicação, podem variar infinitamente segundo os diferentes pontos de partida que se tomem. Ou seja, se é verdade que não existe uma única teoria da comunicação, como quer Sandra Reimão ("Teoria ou Teorias da Comunicação" in INTERCOM-Revista Brasileira de Comunicação, S. Paulo, INTERCOM, Vol. XVII, n. 2, julho-dezembro de 1994, pp. 146170), não menos verdade é que inexiste uma única história, quer dos meios, quer dos processos ou das tecnologias da informação. $\mathrm{O}$ desafio mais provocante, pois, é justamente esta abertura imensa que a área nos concede, não apenas porque é um campo de conheci- mento ainda novo mas porque, justamente, lida com um fenômeno que, por si só, é uma mescla de diferentes fenômenos porque, na verdade, se encontra, se cruza, enriquece e é enriquecido por todos eles. Esta lição de grandeza e, ao mesmo tempo, de humildade, deve ser o grande saldo da leitura deste novo livro de Mattelart que, como sempre, é fascinante, e tão mais fascinante tem se tornado à medida em que o autor, como já frisei a respeito do trabalho anterior publicado em língua portuguesa, distancia-se da camisa-de-força da análise marxista ortodoxa.

MATTELART, Armand - História das teorias da comunicação, S. Paulo, Loyola, 1999, 220 páginas.

\section{Tópicos de Teoria da Comunicação}

Há uMA ABSOluta escassez de manuais que abordem a Teoria da Comunicação ou mesmo a Teoria da Informação. De modo geral, contamos apenas com alguns livros traduzidos, a partir de autores norte-americanos. Em, conseqüência, boa parte dos currículos desenvolvidos em nossos Cursos de Comunicação obrigam os professores a constituir eles mesmos os seus conteúdos, catando, daqui e dali, o material que transmitirão aos alunos. não se precisa dizer que, concomitantemente, o aluno, recém-saído dos bancos do II Grau, enfrenta dificuldades porque não tem a tradição da pesquisa acadêmica.

Por tudo isso, sempre serão bem-vindos os livros de Teoria da Comunicação, mesmo quando parciais, como este Tópicos de Teoria da Comunicação, que não se pretende um livro abrangente, e isto, desde o título.

Escrito por Pedro Gilberto Gomes, ainda recentemente homenageado com o Prêmio Luís Beltrão, Tópicos de Teoria da Comunicação é um livro de militante, aliás, de dupla militância, aquela do professor universitário e a outra, da perspectiva religiosa da comunicação.

A obra começa por desenvolver a questão dos modelos teóricos, abordando em seguida o conceito do que seja uma teoria e as 
relações entre informação e comunicação. Posteriormente, vai-se para um panorama mundial, e especialmente latino-americano da teoria da comunicação, o que é sobretudo importante, se seguirmos a lição de José Marques de Melo, para quem a chamada escola latinoamericana, com seu hibridismo, tem contribuído com perspectivas inovadoras para este campo de conhecimento.

Depois de discutir questões mais gerais como a comunicação de massa e a sociedade, sob uma perspectiva anticapitalista que o aproxima necessariamente da Escola de Francfurt e seus pressupostos teóricos marxistas, Pedro Gilberto Gomes, que é professor da UNISINOS, aborda os mais conhecidos modelos da Teoria da Comunicação, desde Harold Lasswell, os engenheiros da matemática de informação Shannon e Weaver, até o funcionalismo integrativo de Wilbur Schramm, dando especial ênfase a alguns conceitos como a redundância e a retroalimentação (ou feed-back), o código e a mensagem.

O livro dedica dois extensos capítulos às questões da semiótica, para depois abordar algumas perspectivas recentes como o funcionalismo norte-americano, a teoria crítica da Escola de Frankfurt, os estudos culturais de Marshall McLuhan e, enfim, alguns teóricos latino-americanos de maior influência hoje, como Josés Martin-Barbero e Luís Beltrán.

A parte final da obra está dedicada à discuissão das relações entre ética e comunicação e termina por fazer uma mistura complicada entre a doutrina católica e a tradição marxista, na perspectiva da teologia da libertação.

Escrito em linguagem acessível, com boa quantidade de informações e referenciação bibliográfica, o livro peca apenas pela ausência constante de citações bibliográficas confiáveis. Parece que faltou uma revisão cuidadosa e crítica, capaz de fazer com que a toda a citação ou conceito emitido se incluísse necessariamente a fonte, capaz de possibilitar ao eventual leitor a consulta à matriz da qual aquela idéia foi retirada. Então, o que temos é que, em alguns casos, faz-se a citação bibliográfica, e em outros não. Mais que isso, em alguns casos faz-se a citação completa, e em outros não. Tal fato é uma lástima, porque o livro é extremamente útil, graças inclusive, por certo, à experiência de cátedra do professor, de maneira que ele é recomendável a alunos e professores. Mas é, quanto à forma, um discutível exemplo de como não se deve escrever um livro acadêmico.

GOMES, Pedro Gilberto - Tópicos de teoria da comunicação, São Leopoldo, Editora da Unisinos, 1997, 126 páginas.

\section{Trem e cinema - Buster Keaton on the ratilroad}

No II Festival Universitário de Literatura Categoria Ensaio, que a Xerox patrocinou no ano passado, sagrou-se vencedor o professor Mestre em Comunicação Fernando Fábio Fiorese Furtado, que leciona na Universidade Federal de Juiz de Fora. Seu trabalho é um livro intitulado Trem e cinema - Buster Keaton on the railroad, que está agora recebendo publicação em livro.

O trabalho divide-se em dois blocos. No primeiro deles, intitulado "Trem e cinema", o autor desenvolve a perspectiva teórica que aproxima o desenvolvimento tecnológico do trem do desenvolvimento do cinema, visualizados ambos enquanto tecnologia de semelhanças, em especial pela nova maneira de ver que possibilitam e a que obrigam seus passageiros (no trem, colocados no vagão; no cinema, colocados na sala fechada). No segundo bloco, o autor faz a aplicação prática dessa perspectiva para uma leitura das obras de Buster Keaton, especialmente para o aspecto de valorização e humanização da tecnologia então nascente, numa leitura que, sem perder o lado até certo ponto ufanista da conquista, alerta para os riscos que a mesma pode produzir na humanidade.

Mobilizando um corpus teórico tão amplo quanto inusitado, por sua combinação, o que vale sobretudo pela revalorização das hipóteses de Marshal McLuhan, combinadas com as leituras de Walter Benjamin e Paul Virilio, Furtado propõe uma leitura extrema- 
mente instigante, que se inicia praticamente em 3500 a. C., com a invenção da roda, "ferramenta que prologa o movimento rotatório ou seqüencial dos pés"(p.15) que "fundamenta a ess6encia da mecanização (p. 16). Utilizando a periodização de Lewis Mumford, Furtado mostra que esse mesmo princípio serviu para inventar a locomotiva a vapor e depois os primitivos aparelhos cinematográficos. Para evidenciar esta proposta, repassa as diferentes invenções que, desde a camara oscura de Giovanni Battista della Porta, em 1588 (p. 19 e ss), marcaram a história da humanidade:

"A analogia entre as mecânicas do trem e do aparelho cinematográfico explicitase aqui, pois que o sistema de roda dentada solucionou também o problema de tração das primeiras locomotivas construídas pelo engenheiro inglês Richard Trevithcik: Uncle Dick's Puffer (1804) e Catch me who can (1808)" (p. 23).

Furtado mostra haver "semelhanças formais e funcionais da janela do trem e da tela de cinema, o alinhamento do tandem dos vagões e dos fotogramas e a analogia visual entre a película e a estrada de ferro" (p. 27), afirmando ainda que, a partir dessas invenções, houve a necessidade e a obrigação de uma reeducação dos sentidos:

"Os novos ambientes criados pela aceleração mecânica submetem os habitantes dos centros urbanos a um complexo treinamento sensorial, alteranto tanto os comportamentos individuais e sociais quanto as estruturas do pensamento e da sensibi-lidade" (p. 31).

Para Furtado, "uniformidade, continuidade, fragmentação e repetição, colonização mecanicista da vida humana individual e social, [e] mitologização da máquina e da velocidade"(p. 34), são as novas características do ambiente mecânico atingido na passagem do século XIX para o XX. Houve um alargamento de percepção que, por sua vez, resultou em alterações profundas quanto ao "modo natural" de ser e estar no mundo: "Sob os efeitos da velocidade tecnológica, a Weltanschauung do homem moderno conhece os fenômenos da instabilidade cronológica e da relativização da realidade espacial" (p. 37), sintetiza ele.

$\mathrm{Na}$ segunda parte do ensaio, o autor aborda a produção cinematográfica de Buster Keaton que foi, simultaneamente, produtor, diretor, ator e cinegrafista de suas obras, dando especial relevo a Bancando o águia, Nossa hospitalidade e $A$ General, que lhe permitem aplicar os princípios teóricos levantados na prática da criação artística.

Neste caso, Furtado mostra que desde logo o elemento cômico foi pressentido pelos movimentos de vanguarda como o movimento dadaísta e surrealista, que o incluíram em seu discurso, destacando, dentre outros, os primeiros filmes de René Clair, Fernand Leger e, muito especialmente, Louis Buñuel.

Depois, ele dirige sua atenção para a "máquina de rir" em que se constitui o cinema de Buster Keaton, afirmando que

"sem desconsiderar as heranças do espetáculo circense, da commedia dell'arte, do vaudeville e do music-hall, um princípio mecânico inspira a reconstrução paródica do mundo pela comédia burlesca. A aparência de espontaneidade e mproviso das gags resulta de um minucioso planejamento técnico que inclui a análise e racionalização dos mecanismos do efeito cômico e da estrutura da narrativa cinematográfica" (p. 77).

Tudo isso é possível pelo pleno domínio técnico e os amplos conhecimentos científicos que o realizador possui, permitindolhe, ao mesmo tempo, demonstrar "uma crença inarredável na relação harmoniosa entre homem e tecnologia" (p.92) mas, igualmente, denunciar os excessos e extremos em que facilmente se pode cair. Assim, dois procedimentos técnicos são utilizados pelo cineasta, um deles, a "complexa assimilação de elementos tecnomórficos pelo aparelho motor humano"(p. 88) e depois a "metamorfose 
do corpo em máquina [que se refere] aos engates do personagem nas próteses de deslocamento" (p. 96).

Assim, a conseqüência é que,

"apropriando-se do espaço urbano da civilização tecnológica, a comédia burlesca desempenhou papel relevante na produção das grandes configurações do imaginário coletivo do século $\mathrm{XX}$, notadamente no que se refere aos arquétipos da condição tragicômica do homem moderno"(p. 99).

Mais do que simples divertimentos, os filmes de Buster Keaton, assim, transformaram-se em obras privilegiadamente pioneiras na análise crítica do novo contexto. Por isso, seus personagens, "errantes, transitivos e desenraizados [...] trabalham sobre o enigma da tecnologia"(p. 108).

A leitura do texto de Fernando Fábio Fiorese Furtado é tão fascinante quanto o cinema de Keaton e o horizonte analítico que ele propõe. Não se conhecendo os demais textos concorrentes nem a comissão que escolheu este, que o vencedor, não podemos, de qualquer modo, deixar de nos parabenizar pela sua edição. É um excelente pretexto para que se possa refletir, com maior profundidade, a respeito da grande aventura do cinema, do significado das conquistas tecnológicas do século passado, dentre os quais um dos mais importantes foi a locomotiva a vapor, e todos os seus desdobramentos, ao longo do século $X X$.

FURTADO, Fernando Fábio Fiorese Trem e cinema - Buster Keaton on the railroad, São Paulo, Cone Sul, 1998, 139 páginas.

\section{Comunicação \& Discurso}

Lançado durante o $8^{\circ}$ Congresso da COMPÓS, em junho último, em Belo Horizonte, Comunicação $\mathcal{E}$ Discurso, do experiente professor Milton José Pinto é, desde a primeira impressão de leitura, um livro de extrema utilidade. Em primeiro lugar porque o pequenino mas objetivo volume se quer como um texto didático e como tal se organiza. Ele é claro, tem uma estrutura claramente identificável e, além de fazer uma revisão dos principais conceitos e da bibliografia básica sobre o tema, aponta para os múltiplos desdobramentos que o assunto - análise de discurso - não apenas no campo da comunicação social, quanto em outros campos do conhecimento, permite.

Milton José Pinto integra o corpo docente da Universidade Federal do Rio de Janeiro. Gaúcho de nascimento, carioca por adoção, vem desenvolvendo atividades em classe há muitos anos. Tem experiência com a área que escolheu como tema deste livro, e isso fica evidente desde as primeiras páginas.

Dividindo o pequeno e útil volume em três grandes blocos, no primeiro deles, intitulado "Uma síntese difícil", busca historiar o nascimento desta área de estudos no campo da comunicação, mostrando as diferentes análises possíveis, ligando-as as vários campos de conhecimento e, enfim, delimitando, com clareza, o campo por ele escolhido:

“O modelo de análise de discursos que privilegio neste trabalho é (1) dependente do contexto, (2) crítico nos dois sentidos definidos, (3) não confia na letra do texto relacionado-o às forças sociais que o moldaram, (4) não procura interpretar conteúdos, (5) usa um conceito de ideologia ao lado do de discurso, (6) trabalha comparativamente, (7) não usa técnicas estatísticas no sentido acima, e (8) trabalha com as marcas formais da superfície textual"(p. 10).

Lançando mão das análises tradicionais da retórica, com a hermenêutica, a filologia, a retórica em sentido estrito, e a perspectiva polifônica de Bakhtin, Milton José Pinto refere especialmente o francês Michel Pêcheux, na análise francesa do discurso, mas valoriza a leitura ideológica do discurso, assim como seus aspectos semióticos.

Uma preocupação básica do autor é "limitar a proliferação de termos técnicos espe- 
cializados, tão comuns em disciplinas de desenvolvimento recente" (p. 21), permitindose, contudo, aprofundar análises em torno do que denominará de modos de dizer, modos de mostrar, modos de interagir e modos de seduzir (p. 23).

Partindo da evidência da heterogeneidade dos discursos, Milton José Pinto procura mostrar a riqueza das relações estabelecidas entre o emissor, o receptor e a mensagem, a tradicional tríade do processo comunicacional, mostrando as diferentes maneira pelas quais cada um destes elementos constitutivos do discurso tem sido estudado ao longo das décadas. Seja a capa de revistas, seja a obra pictórica clássica ou a embalagem de produtos cotidianos como um pó para suco, todo o objeto presente na realidade concreta é passível de uma leitura, na medida que porta, em si, um ou mais discursos. Na perspectiva sociológica, Milton José Pinto reconhece a relação entre o ideológico e o poder (p. 40 e ss.), mas não reduz a análise a esta perspectiva. Sabe que a contextualização é, no fundo, o elemento de certo modo fundador da interpretação e compreensão corretas de qualquer discurso e por isso admite a importância das mediações (p. 47 e ss.).

Para deixar bem clara a sua proposta de análise, o autor desenvolve algumas análises comparativas, mencionando estudos já clássicos, como os pioneiros de Eliseo Verón, pesquisas que ele próprio orientou junto a alunos seus, no Rio de Janeiro, e, enfim, algumas sugestões mínimas de exercícios que podem ser facilmente retomados pelos leitores alunos em relação ao tema.

No encerramento do volume, Milton José Pinto sugere um roteiro de leituras introdutórias. E se apresenta alguns textos aparentemente referenciais inexistentes em livro, na verdade está provocando o leitor a valerse das novas tecnologias, como a rede WWW, para a busca desses originais, que podem ser solicitados diretamente às universidades em que foram produzidos.

Por tudo isso, Comunicação $\mathcal{E}$ Discurso, graças a um texto tão cientificamente construído quanto de leitura facilitada, por sua orga- nização, torna-se leitura obrigatória para todos aqueles que pretendem avançar por este campo de estudo.

PINTO, Milton José - Comunicação $\mathcal{E}$ discurso, São Paulo, Hacker Editores, 1999,105 páginas.

\section{Os novos cães de guarda}

Serge Halimi PRETENDE denunciar, em Os novos cães de guarda, o que chama de jornalismo de reverência, que seria uma característica do atual jornalismo francês. Para ele, existe uma estreita relação entre o jornalismo e o poder, que se traduz na formação de uma espécie de máfia, integrada por alguns destacados profissionais que, não apenas ganham fantásticas fortunas em sua profissão, quanto se repartem restritivamente os espaços, os elogios e, evidentemente, os interesses dos diferentes espaços da mídia francesa.

Retomando uma expressão de Paul Nizan, a respeito de filósofos que, segundo ele, não realizavam bem a sua missão interrogativa, Serge Halimi arvora-se numa espécie de corregedor da mídia de seu país, atacando especialmente as práticas de alguns dos nomes de maior referencialidade na mídia francesa, como Alain Peyrefite, Alain Touraine, Christine Okrent, André Rousselet, J. Clément, Alain Duhamel, Michel Field, Alain Minc, Anne Sinclair, Jean-Marie Cavada e outros tantos.

Para ele, existe uma relação direta entre o poder econômico e os jornalistas de grande notoriedade. Como, por outro lado, também existe uma relação entre o poder econômico e a política, termina Halimi por pretender denunciar a relação entre o poder econômico, $\mathrm{o}$ poder político e a mídia, o que, segundo ele, é antiético.

Ora, há muito tempo - os teóricos dizem que pelo menos desde o início do século XIX - que esta situação existe. Ou seja, a partir do momento em que a informação se tornou uma mercadoria, estreitaram-se os laços entre o poder econômico e o poder político. Basta ler, dentre outros estudiosos brasi- 
leiros, Ciro Marcondes Filho (Imprensa e capitalismo, S. Paulo, Kairós, 1984), para se ter evidenciada esta realidade. Ela pode não ser a ideal, e por certo não o é. Mas daí a pretender o autor deste livro estar a denunciar uma determinada realidade, como se ela fosse novidade, chega quase ao ridículo. Das duas uma: ou Halimi não se dá conta do mundo em que vive ou então continua sonhando com determinadas utopias inexistentes no mundo capitalista.

Para robustecer sua denúncia, Halimi pretende fazer comparações entre as práticas francesas e norte-americanas, concluindo que existiria maior autonomia na mídia dos Estados Unidos do que na francesa. É provável que os administradores da mídia norte-americana tenham maior cuidado com as emissões e as informações que divulgam. Mas não se pode acreditar, de boa fé, que as relações entre poder econômico e poder político, refletindo-se sobre a relação destes com os jornalistas, seja diversa da realidade que ocorre na França. Observe-se que a administração redacional toma muito cuidado com o que permite ser publicado e a primeira emenda à Constituição norte-americana, se garante a absoluta liberdade de imprensa, obriga igualmente a uma responsabilidade radical dos proprietários de uma empresa de comunicação em relação ao que divulgam. Observe-se o famoso relato de Bob Woodward e Carl Bernstein a respeito do Caso Watergate. No entanto, todos conhecemos a profunda centralização, os oligopólios formados pela chamada indústria cultural, na antiga acepção de Adorno-Horkheimer, atualizada enquanto indústria de consciências, por Enzensberger, focalizada em obra muito bem pesquisada de Armand Mattelart na década de 70 (As multinacionais da cultura, Rio de Janeiro, Civilização Brasileira, 1976).

A impressão que se tem é que Serge Halimi não conseguiu espaço em nenhum segmento, nem mesmo no socialista, que denuncia veementemente, reduzindo às mesmas práticas tanto o direitista Chirac quanto o socialista Mitterand. Na verdade, o discurso trotskista de Halimi só tem uma vanta- gem: mostra o ridículo de certas práticas entre os principais jornalistas franceses, de auto-louvação e entre-citações que, evidentemente, devem ser repudiadas pelos espectadores e leitores destes profissionais em geral. Mas ele próprio acaba por diminuir a força de sua denúncia quando reconhece que alguns dos pretensamente denunciados nem sempre permanecem com as vantagens condenadas, bastando citar-se a situação de Christine Okrent, demitida justamente por quebrar algumas das regras vigentes na mídia francesa.

Bem embasado teoricamente, mas sob uma ótica não sei se ingênua ou apenas escandalosa, o livro de Serge Halimi esgota-se em si mesmo. Sob a capa do discurso acadêmico, tingido de ética indignada, nada mais encontramos que um punhado de fofocas encontráveis até mesmo em publicações como a Caras brasileira. Se se quiser, de fato, discutir e aprofundar as questões éticas desta convivência ou, mesmo, desta conivência, talvez seja melhor ler o norte-americano John Hulteng (Os desafios da comunicação: problemas éticos, Florianópolis, UFSC, 1990), Claude-Jean Bertrand ( $A$ deontologia das mídias, Bauru, EDUSC, 1999) ou ainda Daniel Cornu (Ética da informação, Bauru, EDUSC, 1998), menos panfletários e mais objetivos em suas análises.

HALIMI, Serge - Os novos cães de guarda, Petrópolis, Vozes, 1998, 150 páginas . 